\title{
All-Cause Mortality and Incidence of Major Adverse Cardiac Events in Sickle Cell Nephropathy: A Comparative Study
}

\author{
Kunjan Udani ${ }^{1}$, Nayda Parisio-Poldiak ${ }^{2}$, Julia Campbell ${ }^{3}$, Victor Collier ${ }^{1}$, Pooja Patel ${ }^{1}$ \\ 1. Internal Medicine, Grand Strand Medical Center, Myrtle Beach, USA 2. Medicine, Grand Strand Medical Center, \\ Myrtle Beach, USA 3. Medicine, Edward Via College of Osteopathic Medicine, Spartanburg, USA
}

Corresponding author: Kunjan Udani, kunjan.udani@hcahealthcare.com

\section{Abstract \\ Background}

Sickle cell disease (SCD) is an autosomal recessive disease resulting in hemolytic anemia and recurrent vaso-occlusive events. Consequently, it can result in a broad range of functional and structural renal and cardiac alterations. Chronic kidney disease (CKD), in SCD, is associated with proteinuria, microalbuminuria, and hemoglobinuria. Cardiac complications in SCD include pulmonary hypertension, left ventricular diastolic heart disease, dysrhythmia, and sudden death. In patients with advancing age, cardio-renal dysfunction can have substantial effects on morbidity and mortality. Our primary aim was to compare the incidence of major adverse cardiac events (MACE) and all-cause mortality in sickle cell nephropathy (SCN).

\section{Methods}

In this retrospective study, we used International Classification of Diseases (ICD)-10 codes to identify admissions in 2019 with a diagnosis of MACE with a prior diagnosis of SCD and/or SCN. Our search of the HCA Healthcare Enterprise Data Warehouse for adult patients >18 years yielded 6,693 patients with SCD, of which 658 patients (9.8\%) had SCN. Primary endpoints were incidence of MACE and all-cause mortality. Patients with MACE encompassed those with nonfatal stroke, nonfatal myocardial infarction, and congestive heart failure (CHF) exacerbations. A secondary endpoint was length of stay (LOS). Logistic regression analysis was used for MACE and all-cause mortality. LOS was analyzed using multiple linear regression analysis. Results were considered statistically significant for analyses showing $\mathrm{p}<0.05$. All outcomes were adjusted for demographic variables and comorbidities.

\section{Results}

Logistic regression, after adjustment for comorbidities, demonstrated that SCN patients had significantly higher odds of all-cause mortality (odds ratio [OR] 2.343, $\mathrm{p}=0.035$, 95\% confidence interval [CI] 1.0635.166) compared to patients without SCN. Compared to those without SCN, those with SCN did not have a higher odds of MACE (OR 1.281, $\mathrm{p}=0.265,95 \% \mathrm{CI} 0.828-1.982$ ). Linear regression for LOS did not reveal a significant association with SCN $(p=0.169,95 \%$ CI 0.157-0.899).

Review began 04/09/2021 Review ended 05/10/2021 Published 05/16/2021

() Copyright 2021 Udani et al. This is an open access article distributed under the terms of the Creative Commons Attribution License CC-BY 4.0., which permits unrestricted use, distribution, and reproduction in any medium, provided the original author and source are credited.

\section{Conclusion}

Based on the analysis of 6,693 patients with SCD, SCN was associated with significantly higher odds of allcause mortality. SCN was not associated with significantly higher odds of MACE or prolonged LOS.

Categories: Cardiology, Nephrology, Hematology

Keywords: major adverse cardiac event, mace, sickle cell nephropathy, sickle cell disease, all-cause mortality

\section{Introduction}

Sickle cell disease (SCD) is a hematologic disorder caused by a single base-pair mutation in the gene for the beta-globin chain of adult hemoglobin ( $\mathrm{HbS}$ ) [1]. The disease is characterized by sickle shaped erythrocytes induced by tissue hypoxia or dehydration, leading to vaso-occlusion and hemolytic anemia [2].

Sickle cell patients with severe hemolytic anemia are predisposed to numerous complications such as pulmonary hypertension, ischemic stroke, recurrent infection, acute chest syndrome, deep vein thrombosis, pulmonary embolism, skin ulcers, and impaired vasomotor control [3,4]. Left ventricular diastolic dysfunction, elevated serum levels of N-terminal pro-B-type natriuretic peptide (NT-proBNP), hemoglobinuria, proteinuria, macro-albuminuria, chronic kidney disease (CKD), and coronary disease are all "biomarkers" that have been shown to help identify adult patients with SCD who are at a higher risk of morbidity and death [5]. 
The rich vascularity in the kidney coupled with low oxygen tension may make it more susceptible to sickle cell damage, leading to devastating effects, which include sickle cell-induced renal failure and sickle cell nephropathy (SCN) [2]. Microalbuminuria, an early manifestation of SCN, is prevalent in nearly $60 \%$ of patients aged $>45$ years but only $4 \%-12 \%$ of patients will develop serious, life-threatening end-stage renal disease [6]. Serial monitoring of the estimated glomerular filtration rate (eGFR) allows for evaluation of the progression of SCN. Rapid decline in eGFR has been associated with higher systolic blood pressure and proteinuria [7].

Cardiovascular disease was the most common cause of death in SCD patients from 1999-2009 [8,9,10]. Major adverse cardiac events (MACE) associated with SCD include cardiomyopathy, hypertension, heart failure, myocardial infarction, arrhythmias, and sudden death $[11,12]$. The spectrum of functional and structural renal and cardiac alterations in sickle cell hemoglobinopathy is broad; however, morbidity and mortality from end-organ dysfunction, especially cardio-renal dysfunction, are substantial [13].

SCD patients have elevated levels of systemic inflammatory biomarkers that suggest a tendency towards endothelial dysfunction, cardiovascular and thromboembolic risk [14]. CKD is a well-defined risk factor for cardiovascular events, but the characterization of a potential additional cardiovascular risk in the population with SCD and CKD has not been defined [15]. This study aims to compare all-cause mortality and incidence of MACE in SCN.

\section{Materials And Methods}

In this retrospective study, we evaluated adult patients (age $\geqslant 18$ years) hospitalized with a diagnosis of MACE with a prior diagnosis of SCD and SCN during 2019 ( $n=6,693)$. To acquire the dataset, we used International Classification of Diseases (ICD)-10 codes to query the HCA Healthcare Enterprise Data Warehouse, which encompasses 186 hospitals in 21 states across the United States. Patients younger than 18 years or undergoing outpatient surgery were excluded. This study received an institutional IRB exempt determination (2019-517).

Data were analyzed using SAS 9.4 (SAS Institute, Cary, NC) and IBM Statistical Package for Social Sciences (SPSS), version 24 (IBM Corp., Armonk, NY). Primary endpoints were incidence of MACE and all-cause mortality. Patients with MACE encompassed those with nonfatal stroke, nonfatal myocardial infarction, and congestive heart failure (CHF) exacerbations. A secondary endpoint was length of stay (LOS). Multivariate logistic regression was used to assess the relationships between MACE, CHF, and mortality. Multiple linear regression analysis was used to assess relationships with LOS. All outcomes were adjusted for demographic variables and comorbidities. An alpha level of 0.05 , with possible correction for multiple comparisons, was used for type I error rate.

\section{Results}

The study cohort included 6,693 adults patients identified with SCD with an average age of $36.34 \pm 13.8$ years. Table 1 summarizes the demographics of patients with SCD and related comorbidities. Patients were more likely to be African American (90.2\%) and female (65.1\%). 9.8\% of the cohort had SCN, 3.6\% had MACE, $12.8 \%$ had asthma, $9.1 \%$ were diabetic and $11 \%$ were tobacco users. The average age for patients who died in the hospital was 47.67 years, while the average for patients diagnosed with MACE and CHF were 52.83 and 52.46 years, respectively (Figure 1 ).

\begin{tabular}{|c|c|c|}
\hline Sickle Cell Disease $(n=6,693)$ & Number of Patients & Percentage \\
\hline \multicolumn{3}{|l|}{ Sex } \\
\hline Male & 2337 & 34.9 \\
\hline Female & 4356 & 65.1 \\
\hline \multicolumn{3}{|l|}{ Race } \\
\hline Black & 6037 & 90.2 \\
\hline White & 295 & 4.4 \\
\hline Other & 361 & 5.4 \\
\hline \multicolumn{3}{|l|}{ Cardiovascular } \\
\hline Coronary Disease & 245 & 3.6 \\
\hline MACE & 242 & 3.6 \\
\hline Congestive Heart Failure & 222 & 3.3 \\
\hline
\end{tabular}




\section{Cureus}

\begin{tabular}{|c|c|c|}
\hline Peripheral Vascular Disease & 35 & 0.5 \\
\hline Myocardial Infarction & 22 & 0.3 \\
\hline Cardiac Arrest & 20 & 0.2 \\
\hline Ventricular Arrhythmia & 20 & 0.2 \\
\hline Cardiogenic Shock & 11 & 0.1 \\
\hline Stroke & 4 & 0.05 \\
\hline \multicolumn{3}{|l|}{ Pulmonary } \\
\hline Asthma & 859 & 12.8 \\
\hline Pulmonary Embolism & 62 & 0.9 \\
\hline Acute Respiratory Failure & 43 & 0.6 \\
\hline COPD & 14 & 0.2 \\
\hline \multicolumn{3}{|l|}{ Renal } \\
\hline Nephropathy & 658 & 9.8 \\
\hline Chronic Kidney Disease & 544 & 8.1 \\
\hline Acute Renal Failure & 413 & 6.1 \\
\hline Proteinuria & 61 & 0.9 \\
\hline Hemoglobinuria & 1 & 0.01 \\
\hline \multicolumn{3}{|l|}{ GI/Liver } \\
\hline Noninfectious Hepatitis & 81 & 1.2 \\
\hline Acute Liver Failure & 15 & 0.2 \\
\hline \multicolumn{3}{|l|}{ Neuro } \\
\hline Transient Ischemic Attack & 16 & 0.2 \\
\hline \multicolumn{3}{|l|}{ Endocrine } \\
\hline Diabetes & 611 & 9.1 \\
\hline Obesity & 555 & 8.2 \\
\hline Thyrotoxicosis & 23 & 0.3 \\
\hline Shock & 10 & 0.1 \\
\hline \multicolumn{3}{|l|}{ Other } \\
\hline Tobacco Abuse & 740 & 11.0 \\
\hline Recreational Drug Use & 430 & 6.4 \\
\hline Cannabis & 230 & 3.4 \\
\hline Opioid & 153 & 2.2 \\
\hline Cocaine & 79 & 1.1 \\
\hline Alcohol Abuse & 40 & 0.5 \\
\hline Amphetamine & 25 & 0.3 \\
\hline
\end{tabular}

TABLE 1: Demographics of patients with sickle cell disease and related comorbidities MACE: major adverse cardiac events, COPD: chronic obstructive pulmonary disease, 


\section{Cureus}

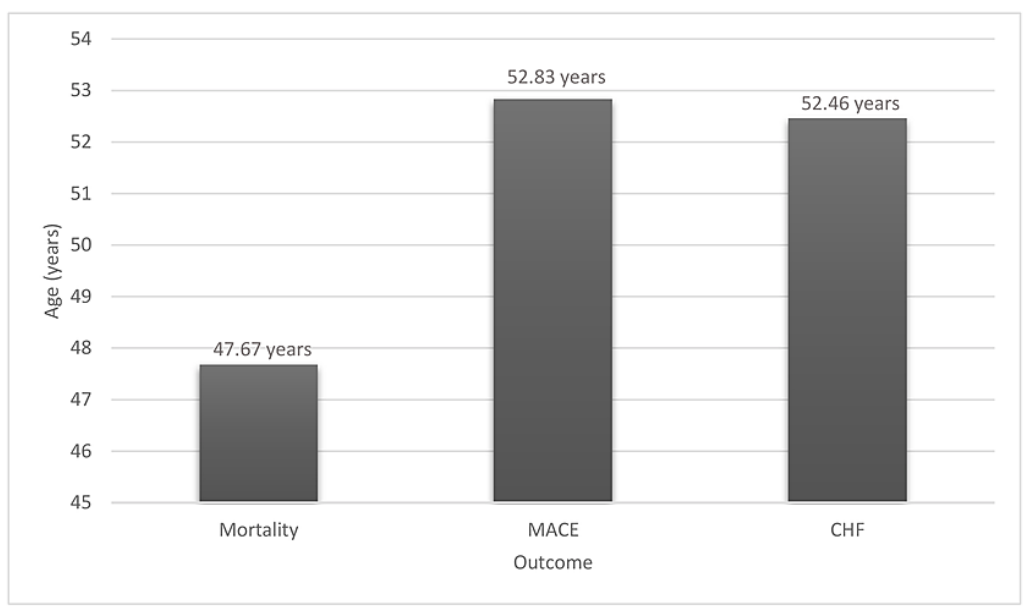

\section{FIGURE 1: Sickle cell disease and outcome variable}

MACE: major adverse cardiac events, CHF: congestive heart failure

SCN patients had an average LOS of 4.76 days compared to 2.52 days for sickle cell patients without nephropathy (Figure 2). On multivariate linear regression, SCN patients had a 0.371-day longer stay compared to patients without nephropathy, which did not yield a significant relationship between LOS and SCN $(p=0.169,95 \%$ confidence interval (CI) $(-0.157,0.899))$.

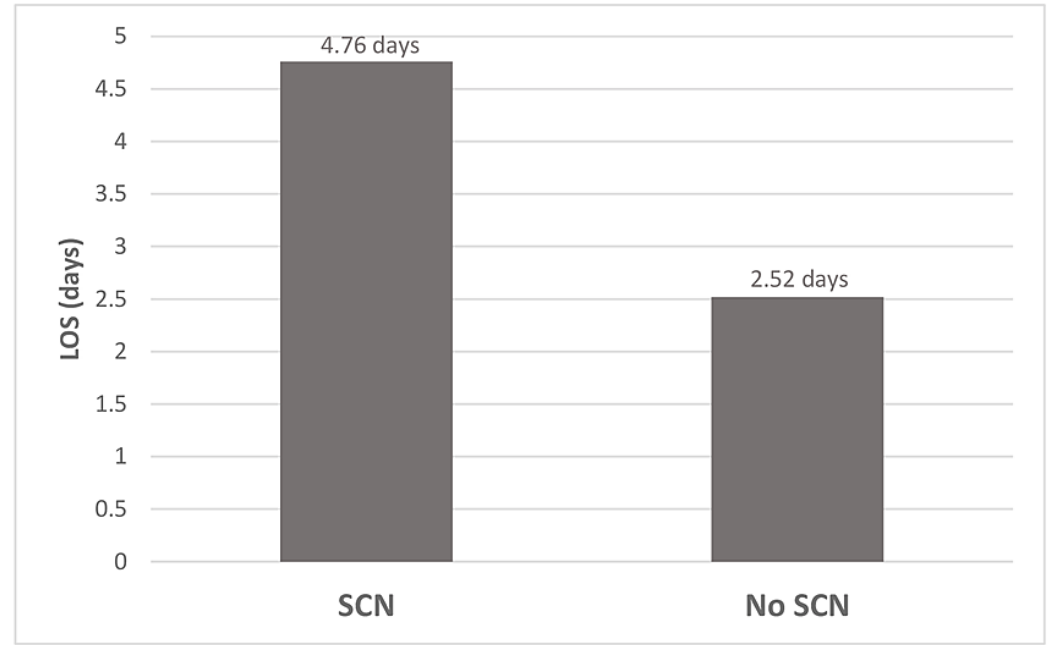

FIGURE 2: Length of stay of patients with and without sickle cell nephropathy

LOS: length of stay, SCN: sickle cell nephropathy

As seen in Table 2, patients with SCN had a significantly higher mortality [odds ratio (OR) $2.343 \mathrm{p}=0.035$ 95\% CI $(1.063,5.166)]$ compared with patients without nephropathy. There was trend toward an increased risk of CHF exacerbations [OR 1.438, p = 0.109, 95\% CI $(.923,2.241)]$, but the OR for MACE events was not 
significant [OR 1.281, $\mathrm{p}=0.265,95 \% \mathrm{CI}(.828,1.982)]$, nor was the regression for LOS $(\mathrm{p}=0.169,95 \%$ CI $(-$ $.157, .899))$.

\begin{tabular}{|c|c|c|c|}
\hline Nephropathy outcome & OR & P value & $95 \% \mathrm{Cl}$ \\
\hline Mortality & 2.343 & .035 & $1.063-5.166$ \\
\hline CHF & 1.438 & .109 & $0.923-2.241$ \\
\hline MACE & 1.281 & .265 & $0.828-1.982$ \\
\hline \multicolumn{4}{|c|}{$\begin{array}{l}\text { TABLE 2: Odds ratio for mortality, CHF and MACE comparing patients with and without sickle ce } \\
\text { nephropathy }\end{array}$} \\
\hline \multicolumn{4}{|c|}{ OR: odds ratio, Cl: confidence interval, CHF: congestive heart failure, MACE: major adverse cardiac events } \\
\hline
\end{tabular}

\section{Discussion}

This retrospective cohort study compared the incidence of MACE and all-cause mortality in patients with SCN. The key findings show that patients with nephropathy did not have a significant increase in MACE; however, these same patients had a significant increase in mortality, such that they were 2.3 times more likely to die when compared to patients without nephropathy. It has been well established in the literature that repeated vaso-occlusive crises are responsible for SCN that may range from renal dysfunction to CKD [2]. In addition, an association has been suggested between glomerulosclerosis and atherosclerosis [16]. The pathogenic process of oxidative stress atherosclerosis augments the progression of activated macrophages with foam cell formation that contribute to both the progression of glomerulosclerosis and atherosclerosis [17]. Evidence from transgenic, sickle cell mice supports the association between progression of renal disease and cardiovascular disease due to nitric oxide-mediated oxidant stress injury [18]. These data suggest that preventive strategies for cardiovascular disease and atherosclerosis may prevent the progression of kidney disease.

While subclinical renal abnormalities begin at an earlier age, end-stage renal disease in SCN usually occurs between the third and fifth decades of life [19,20]. Platt et al. reported an 18\% mortality for SCD patients with organ dysfunction, particularly renal dysfunction. Notable predictors of mortality include progression of renal disease, severe anemia, seizures, acute chest syndrome, and more symptomatic disease [21]. Similarly, Hamideh and Alvarez reported mortality in $16.4 \%$ of patients with renal disease [10]. In a prospective study following 105 patients over five years, Galloway-Blake et al. reported a 38\% mortality rate (40 out of 105 patients) for patients with SCD [22]. In our study of 6,693 SCD patients, we found an increased OR for mortality, which agrees with the aforementioned studies. We found that the average age for mortality was 47.67 years (Figure 1). This roughly agrees with the previously published data, which noted an average age of death at 35-44 years for males and $45-54$ years for females [10,21].

Sickled erythrocytes adhere to vascular endothelium, resulting in a pro-inflammatory state, with subsequent platelet aggregation and vasoconstriction. This leads to thrombi formation in cerebral and cardiac blood vessels, causing strokes and myocardial infarction [23,24]. Cardiac blood supply could be compromised during sickling crises, causing hypoxia as well as myocardial ischemia. Recurrent myocardial ischemia often leads to CHF [25]. Additionally, chronic anemia due to SCD causes left ventricular dilation, eccentric hypertrophy, and diastolic dysfunction to maintain adequate cardiac output $[5,12]$. We found a significantly increased risk of CHF exacerbations, thus confirming that SCD plays a key role in the development of CHF.

When examining the impact of SCN on the duration of hospitalization, we did not observe a significant association between SCN and LOS. On the contrary, Yeruva et al. observed a 1.6-day increase in LOS for SCD patients diagnosed with CKD and 3.2 days for acute renal failure (ARF) [26]. In present-day medicine, LOS is a relevant topic due to the importance given to cost-effective high-value care. The chronicity of renal disease in SCD raises concern for high economic burden [27-29].

Our study has some potential limitations. Patients were identified using discharge ICD-10 codes through an electronic administrative database. The accuracy of the ICD-10 codes is influenced by several factors, including quality of communication between physicians and patients, clinicians' expertise and precision of the diagnoses in medical records as well as coders' experience and attention to choosing the best code. Hence, as an administrative database, the HCA Healthcare Electronic Data Warehouse may have variations in the degree of detail and accuracy. Additionally, this study had an intrinsic limitation for having a retrospective design with only one year of data collection, which may have affected its results.

\section{Conclusions}


Based on the analysis of 6,693 patients with SCD, SCN was associated with significantly higher odds of allcause mortality. SCN was not associated with significantly higher odds of MACE or prolonged LOS. While SCN may be associated with all-cause mortality, further studies are warranted to understand the association between SCN and cardiovascular complications.

\section{Additional Information \\ Disclosures}

Human subjects: All authors have confirmed that this study did not involve human participants or tissue. Animal subjects: All authors have confirmed that this study did not involve animal subjects or tissue. Conflicts of interest: In compliance with the ICMJE uniform disclosure form, all authors declare the following: Payment/services info: All authors have declared that no financial support was received from any organization for the submitted work. Financial relationships: All authors have declared that they have no financial relationships at present or within the previous three years with any organizations that might have an interest in the submitted work. Other relationships: All authors have declared that there are no other relationships or activities that could appear to have influenced the submitted work.

\section{Acknowledgements}

Statistical analysis by Christian Vandever

\section{References}

1. Marengo-Rowe AJ: Structure-function relations of human hemoglobins. Proc (Bayl Univ Med Cent). 2006, 19:239-45. 10.1080/08998280.2006.11928171

2. Gargiulo R, Pandya M, Seba A, Haddad RY, Lerma EV: Sickle cell nephropathy. Dis Mon. 2014, 60:494-9. 10.1016/j.disamonth.2014.08.004

3. Kato GJ: New insights into sickle cell disease: mechanisms and investigational therapies . Curr Opin Hematol. 2016, 23:224-32. 10.1097/MOH.0000000000000241

4. Reeves SL, Jary HK, Gondhi JP, Kleyn M, Spector-Bagdady K, Dombkowski KJ: Incidence, demographic characteristics, and geographic distribution of sickle cell trait and sickle cell anemia births in Michigan, 1997-2014. Mol Genet Genomic Med. 2019, 7:e795. 10.1002/mgg3.795

5. Gladwin MT: Cardiovascular complications in patients with sickle cell disease . Hematology Am Soc Hematol Educ Program. 2017, 2017:423-30. 10.1182/asheducation-2017.1.423

6. Sharpe CC, Thein SL: Sickle cell nephropathy - a practical approach . Br J Haematol. 2011, 155:287-97. 10.1111/j.1365-2141.2011.08853.x

7. Xu JZ, Garrett ME, Soldano KL, Chen ST, Clish CB, Ashley-Koch AE, Telen MJ: Clinical and metabolomic risk factors associated with rapid renal function decline in sickle cell disease. Am J Hematol. 2018, 93:1451-60. 10.1002/ajh.25263

8. Sipahi I, Tuzcu EM, Schoenhagen P, et al.: Effects of normal, pre-hypertensive, and hypertensive blood pressure levels on progression of coronary atherosclerosis. J Am Coll Cardiol. 2006, 48:833-8. 10.1016/j.jacc.2006.05.045

9. Elmariah H, Garrett ME, De Castro LM, et al.: Factors associated with survival in a contemporary adult sickle cell disease cohort. Am J Hematol. 2014, 89:530-5. 10.1002/ajh.23683

10. Hamideh D, Alvarez O: Sickle cell disease related mortality in the United States (1999-2009) . Pediatr Blood Cancer. 2013, 60:1482-6. 10.1002/pbc.24557

11. Fitzhugh CD, Lauder N, Jonassaint JC, et al.: Cardiopulmonary complications leading to premature deaths in adult patients with sickle cell disease. Am J Hematol. 2010, 85:36-40. 10.1002/ajh.21569

12. Gladwin MT, Sachdev V: Cardiovascular abnormalities in sickle cell disease . J Am Coll Cardiol. 2012, 59:1123-33. 10.1016/j.jacc.2011.10.900

13. Abo-Zenah H, Moharram M, El Nahas AM: Cardiorenal risk prevalence in sickle cell hemoglobinopathy . Nephron Clin Pract. 2009, 112:c98-c106. 10.1159/000213897

14. Naik RP, Wilson JG, Ekunwe L, et al.: Elevated D-dimer levels in African Americans with sickle cell trait . Blood. 2016, 127:2261-3. 10.1182/blood-2016-01-694422

15. Go AS, Chertow GM, Fan D, McCulloch CE, Hsu CY: Chronic kidney disease and the risks of death, cardiovascular events, and hospitalization. N Engl J Med. 2004, 351:1296-305. 10.1056/NEJMoa041031

16. Diamond JR: Analogous pathobiologic mechanisms in glomerulosclerosis and atherosclerosis . Kid Int. 1991, 31:29-34.

17. Ross R: Atherosclerosis--an inflammatory disease. N Engl J Med. 1999, 340:115-26. 10.1056/NEJM199901143400207

18. Bank N, Kiroycheva M, Singhal PC, Anthony GM, Southan GJ, Szabo C: Inhibition of nitric oxide synthase ameliorates cellular injury in sickle cell mouse kidneys. Kidney Int. 2000, 58:82-9. 10.1046/j.15231755.2000.00143.x

19. Saborio P, Scheinman J: Sickle cell nephropathy. J Am Soc Nephrol. 1999, 10:187-192.

20. Tejani A, Phadke K, Adamson O, Nicastri A, Chen CK, Sen D: Renal lesions in sickle cell nephropathy in children. Nephron. 1985, 39:352-5. 10.1159/000183404

21. Platt OS, Brambilla DJ, Rosse WF, Milner PF, Castro O, Steinberg MH, Klug PP: Mortality in sickle cell disease. Life expectancy and risk factors for early death. N Engl J Med. 1994, 330:1639-44. 10.1056/NEJM199406093302303

22. Galloway-Blake K, Reid M, Walters C, Jaggon J, Lee MG: Clinical factors associated with morbidity and mortality in patients admitted with sickle cell disease. West Indian Med J. 2014, 63:711-6. 10.7727/wimi.2014.012 


\section{Cureus}

23. Switzer JA, Hess DC, Nichols FT, Adams RJ: Pathophysiology and treatment of stroke in sickle-cell disease: present and future. Lancet Neurol. 2006, 5:501-12. 10.1016/S1474-4422(06)70469-0

24. Martin CR, Johnson CS, Cobb C, Tatter D, Haywood LJ: Myocardial infarction in sickle cell disease. J Natl Med Assoc. 1996, 88:428-432.

25. Pannu R, Zhang J, Andraws R, Armani A, Patel P, Mancusi-Ungaro P: Acute myocardial infarction in sickle cell disease: a systematic review. Crit Pathw Cardiol. 2008, 7:133-8. 10.1097/HPC.0b013e3181668ac3

26. Yeruva SL, Paul Y, Oneal P, Nouraie M: Renal failure in sickle cell disease: prevalence, predictors of disease, mortality and effect on length of hospital stay. Hemoglobin. 2016, 40:295-9. 10.1080/03630269.2016.1224766

27. Amendah DD, Mvundura M, Kavanagh PL, Sprinz PG, Grosse SD: Sickle cell disease-related pediatric medical expenditures in the U.S. Am J Prev Med. 2010, 38:S550-6. 10.1016/j.amepre.2010.01.004

28. Ballas SK: The cost of health care for patients with sickle cell disease . Am J Hematol. 2009, 84:320-2. 10.1002/ajh.21443

29. Kauf TL, Coates TD, Huazhi L, Mody-Patel N, Hartzema AG: The cost of health care for children and adults with sickle cell disease. Am J Hematol. 2009, 84:323-7. 10.1002/ajh.21408 